\title{
O DIREITO DE CONSENTIMENTO PRÉVIO DO TITULAR PARA O TRATAMENTO DE DADOS PESSOAIS NO CIBERESPAÇO
}

\author{
Plínio Rebouças de Moura ${ }^{1}$ \\ Diogo de Calasans Melo Andrade ${ }^{2}$
}

Resumo: $\mathrm{O}$ direito à privacidade é um direito humano, fundamental e da personalidade, que ganha novos contornos na sociedade da informação. A tutela jurídica do direito à vida privada, neste particular, encontra guarida na Lei n. 13.709/18 e em normas que compõem um microssistema legislativo de proteção de dados pessoais. O enfoque essencial é o consentimento prévio do titular para o tratamento dos dados privativos no ciberespaço, observando-se parâmetros e exceções previstos no ordenamento jurídico pátrio, analisando-se comparativamente normas internacionais, doutrina e jurisprudência pertinentes, através de uma abordagem qualitativa do problema, pesquisa de natureza exploratória e procedimento bibliográfico e documental.

Palavras-chave: Privacidade. Dados pessoais. Consentimento prévio. Ciberespaço. Lei n. $13.709 / 18$.

\section{THE RIGHT OF PRIOR CONSENT OF THE HOLDER TO THE PROCESSING OF PERSONAL DATA IN CYBERSPACE}

\begin{abstract}
The right to privacy is a human right, fundamental and personality, that gains new contours in the information society. The legal protection of the right to privacy, in this particular case, is enshrined in Law no. 13.709/18 and in standards that make up a microsystem for the protection of personal data. The main focus is the prior consent of the holder to the treatment of private data in cyberspace, observing parameters and exceptions provided in the Brazilian legal order, comparing international standards, relevant doctrine and jurisprudence, through a qualitative approach to the problem, research of exploratory nature and bibliographic and documentary procedure.
\end{abstract}

Key-words: Privacy. Personal data. Prior Consent. Cyberspace. Law n. 13,709/18.

\section{INTRODUÇÃO}

\footnotetext{
${ }^{1}$ Mestrando em Direitos Humanos, pelo Programa de Pós Graduação em Direito da Universidade Tiradentes. Email: plinio.rmoura79@gmail.com.

${ }^{2}$ Doutor em Direito Político e Econômico pela Universidade Mackenzie. Mestre em Direito pela UFS. Professor universitário da Graduação e do Mestrado em Direitos Humanos da Universidade Tiradentes. E-mail: contato@diogocalasans.com.
} 
O direito à privacidade é objeto de tutela específica dentro dos estudos sobre direitos humanos, de igual sorte figurando no arcabouço dos direitos da personalidade e, ainda, com presença marcante no rol de direitos da personalidade.

Será destacado que os contornos específicos do direito à vida privada é relativamente recente, embora seja possível delimitar seus contornos axiológicos em diferentes fases, seja no direito comparado, seja no ordenamento jurídico pátrio.

Neste trabalho, o estudo da privacidade está concentrado em um viés hodierno e complexo: o tratamento de dados pessoais no ciberespaço.

Dentro desse tema ainda amplo, o texto promove um recorte sobre um dos requisitos essenciais para a circulação de informações privativas na rede, com enfoque no recente microssistema legislativo brasileiro de proteção de dados pessoais: o consentimento.

O consentimento do titular das informações privativas é objeto de regulamentação na nova Lei Geral de Proteção de Dados, sob n. 13.709/18, publicada em 15.08.2018 (vigência após 18 meses - prevista para 16 de fevereiro de 2020, agora modificada para 24 meses, prevista para 16 de agosto de 2020, diante do advento da MP 869/2018), com forte impacto no ordenamento jurídico brasileiro e inspiração na legislação alienígena mais recente, especialmente no Regulamento Geral sobre a Proteção de Dados (RGPD) n. 2016/679, da União Europeia, datado de 2016 e em vigor desde o mês de maio de 2018.

Pretende-se salientar, ainda, que a norma em comento compõe uma estrutura legislativa recente, que tem como foco o tratamento de dados de pessoas físicas e jurídicas que circulam no "ciberespaço", perfazendo um novo sistema legislativo ao qual também integram: a) o Marco Civil da Internet (Lei n. 12.965/2014); b) o Regulamento do Marco Civil da Internet (Decreto n. 8.771/16); c) a Lei de Acesso à Informação (Lei n. 12.527/11); d) o Regulamento da Lei de Informação (Decreto n. 7.724/12); e) a norma do Cadastro Positivo (Lei $\mathrm{n}^{\mathrm{o}}$ 12.414/2011); f) o Cadastro Único para Programas Sociais do Governo Federal (Decreto n. 6.135/07); g) a Lei do Sigilo (Lei Complementar n. 105/2001); h) a regulamentação do Habeas Data (Lei n. 9.507/97); i) as normas protetivas da Dignidade da Pessoa Humana e dos Direitos da Personalidade, especialmente no que se refere ao Direito à Privacidade, desde a Constituição Federal até o Código Civil e o de Defesa do Consumidor.

A partir da observação sistemática dos textos normativos acima, além da doutrina e jurisprudência em construção, tem-se como principal objetivo promover um estudo crítico 
sobre a autonomia do titular que tem o poder decisório de anuir ou não com o tratamento de informações pessoais, sem olvidar as exceções ao próprio direito de consentir previamente.

O texto enfrenta uma pergunta atual e desafiadora: qual o grau de informação, autonomia e paridade contratual que o titular de dados pessoais possui para obstar ou limitar o tratamento de tais informações no mercado alimentado pela rede mundial de computadores, preservando seu direito à privacidade?

Se não há uma resposta exata ao questionamento em testilha, o trabalho em comento poderá, ao menos, apresentar uma visão crítica e sistêmica da recepção jurídica às novas tecnologias e seu impacto na vida das pessoas, revelando caminhos mais seguros para uma proteção efetiva ao direito humano à privacidade.

O caminho traçado no artigo concluirá, ao fim, que o consentimento prévio do titular, na prática, é um requisito pouco eficaz de proteção do indivíduo, que dependerá muito mais de um sistema de controle verdadeiramente protetivo, para tornar minimamente realista a tarefa de salvaguarda dos seus dados privativos.

\section{A EVOLUÇÃo GERACIONAL DO DIREITO À PRIVACIDADE DE DADOS PESSOAIS}

Os novos contornos do direito à privacidade de dados na "sociedade em rede", expressão consagrada no direito alienígena (CASTELLS, 2006), ensejaram o surgimento de normas específicas para regulamentação mais próxima da realidade, além de recente produção doutrinária e jurisprudencial.

Nos itens seguintes, o diagrama legislativo será analisado em suas principais fases e objetos de tutela, sempre acompanhados dos correspondentes contornos doutrinários e jurisprudenciais, tomando-se como centro do estudo o papel do consentimento do titular, que se destaca como pressuposto essencial para o tratamento de dados, no contínuo, veloz e economicamente relevante fluxo da "galáxia da internet" (CASTELLS, 2004).

A partir da problematização apresentada no capítulo introdutório, com lastro no direito à privacidade na sociedade digital, o primeiro passo para estudar o papel do consentimento do titular de dados pessoais cinge-se na análise da evolução legislativa que se debruça sobre o tema. A pesquisa sobre as normas jurídicas que envolvem o assunto demanda uma distinção 
conceitual entre os arcabouços legais referenciados. Parte-se da premissa tradicional que diferencia direitos humanos, fundamentais e da personalidade.

Nessa linha, cite-se didática pontuação doutrinária (FARIAS, NETTO e ROSENVALD, 2018, p. 196-197):

\begin{abstract}
Direitos Humanos é uma expressão que tende a constar em tratados internacionais (...). Abrangem não só os direitos da pessoa humana em si (vida, honra, intimidade), mas também os direitos sociais - direito ao trabalho, por exemplo -, e também os direitos políticos - como o direito de participar ativamente da vida política do Estado, por exemplo. Não é difícil perceber, nesse contexto, que os direitos humanos gozam de um espectro mais amplo que os direitos da personalidade. (...) Os direitos fundamentais são os direitos humanos que lograram inserção nos textos constitucionais. São direitos consagrados, portanto, nas constituições. (...) Lembremos que nossa Constituição, no Título II, consagra os direitos e garantias fundamentais. (...) Já os direitos da personalidade são os direitos fundamentais, estudados e desenvolvidos pela doutrina do direito privado, a partir de Otto Von Gierke. Não só, por certo, na doutrina do direito privado, mas também e sobretudo nas normas jurídicas civis. Possuem forte ligação com a proteção da dignidade humana, em suas múltiplas dimensões, materiais e imateriais.
\end{abstract}

A par das distinções formais entre direitos humanos, fundamentais e da personalidade, é inegável que a privacidade está inserida nas três categorias. É um direito humano, à medida que a proteção à vida privada está prevista no art. 12, da Declaração Universal dos Direitos Humanos (DUDH, 1948), bem como no art. 11.2, da Convenção Americana sobre Direitos Humanos (Pacto de San José, Costa Rica, 1969). É também um direito fundamental, previsto diretamente no art. $5^{\circ}, \mathrm{X}$, da Constituição Federal do Brasil. À três, é erigido à categoria de direito da personalidade, conforme dicção expressa do art. 21, do Código Civil Brasileiro de 2002: “A vida privada da pessoa natural é inviolável, e o juiz, a requerimento do interessado, adotará as providências necessárias para impedir ou fazer cessar ato contrário a esta norma.”.

Essa construção jurídica protetiva da vida privada remonta ao século XIX, a partir do artigo publicado na Harvard Law Review, intitulado The right of privacy (WARREN e BRANDEIS, 1890). Nessa primeira obra específica sobre o tema, os Autores lamentam a falta de legislação sobre o direito à privacidade, defendem a formulação de normas eficazes de proteção à propriedade, referindo-se aos impactos avanços tecnológicos da época.

Nessa acepção inicial, o direito à vida privada foi concebido com enfoque na proteção do núcleo familiar e com forte influência no modelo proprietário, de caráter mais elitista. Pode-se afirmar que "a privacidade acabaria identificada como um direito da "era de 
ouro da burguesia', limitado às pessoas ricas e famosas, preocupadas em manter sua vida íntima à salvo da bisbilhotice alheia" (SCHEREIBER, 2014, p. 137).

Naturalmente, a evolução do direito privado, a partir da consolidação da aproximação com o direito público, elevou direitos eminentemente civis (como o direito à privacidade), que decorrem de um conceito amplo de vida digna, à categoria de direitos humanos, fundamentais e da personalidade, como já explicitado nos parágrafos anteriores.

Por outro lado, se as invenções advindas da revolução industrial motivaram as preocupações externadas por Warren e Brandeis, o ordenamento jurídico se depara hodiernamente com tecnologias muito mais dinâmicas e invasivas. Assim é que o presente estudo, como já adiantado desde a introdução, tem como enfoque o direito à privacidade de dados pessoais no ciberespaço.

Neste aspecto, a doutrina (DONEDA, 2011) reconhece que regulamentação da proteção de dados pessoais, no direito comparado e no âmbito nacional, passou por algumas fases que, pelo menos para fins didáticos, revelam a evolução histórica dos principais institutos legais que abordam o tema.

Na primeira geração, situada entre o período pós-guerras e a década de 1970, são destacadas as normas voltadas à regulamentação técnica de bancos de dados governamentais, como o faz o Privacy Act norte-americano de 1974.

Acontece que o processamento de dados não pode ser controlado em bancos únicos, e muito menos na exclusiva esfera da administração pública. Assim, no final da década de 1970, novas leis passaram a disciplinar o tema de forma mais ampla, vinculando claramente o direito à privacidade ao processamento de dados, como se vislumbra das primeiras leis da Alemanha (1977) e da França (1978) sobre o tema, consideradas como exemplos da segunda fase ou geração.

A passagem da segunda para a terceira geração de normas jurídicas sobre a privacidade de dados tem no consentimento o ponto central, justamente o que se pretende discutir no presente trabalho. Como pontua a doutrina Danilo Doneda (2011, p. 97): "Uma terceira geração de leis, surgida na década de 1980, procurou sofisticar a tutela dos dados pessoais (...) proporcionando o efetivo exercício da autodeterminação informativa". Um marco normativo da terceira fase de leis sobre a privacidade de dados é a privacy guidelines de 1980, da OCDE (Organização para a Cooperação e Desenvolvimento Econômico). A 
norma em comento traz princípios norteadores da atividade de tratamento de informações privativas, conhecidos como Fair Information Practice Principles/FIPPs, com enfoque especial no controle do cidadão sobre seus dados pessoais (BIONI, 2018).

Por fim, a doutrina pontua que o momento atual é o do surgimento de uma quarta geração de leis, como as Diretivas Europeias de proteção de dados (Diretiva 95/46/CE e a Diretiva 2000/58/CE), que têm como diferencial uma ampliação do alcance da privacidade e um instrumental mais elaborado de proteção do cidadão, reconhecendo o desequilíbrio existente nas relações dessa natureza. Tais normas, entretanto, reduzem o protagonismo do consentimento do titular (MENDES, 2014).

A propósito, convém ressaltar que norma mais recente emanada do Parlamento Europeu, a GDPR (General Data Protection Regulation) n. 2016/679, segue a linha do consentimento informado e protetivo do cidadão em relação aos dados pessoais (norma de quarta geração). Nesta dicção, o art. $6^{\circ}$, I, impõe, para fins de licitude de tratamento, que o titular tenha manifestado seu consentimento.

\section{ANÁlise do PAPEL do CONSENTIMENTO PRÉVIO dO TITUlaR MICROSSISTEMA LEGISLATIVO DE PROTEÇÃO DE DADOS PESSOAIS}

Uma primeira análise da evolução legislativa internacional demonstra a relevância do consentimento do titular nas políticas de proteção da privacidade de dados.

No direito brasileiro, essa evolução é perceptível, também, no histórico legislativo sobre o assunto. Já se pontuou o caráter constitucional do direito fundamental à vida privada, também caracterizado como um direito da personalidade, no art. 21, do CC/02.

Especificamente em relação à tutela dos dados privativos, algumas normas são relevantes e merecem citação, mais uma vez com o recorte especial sobre o tema central do presente trabalho: o consentimento do titular.

Com efeito, o Código de Defesa do Consumidor (1990), ao tratar do caráter público dos chamados "Bancos de Dados", em seu art. 43, regulamenta a atividade de tais instituições centralizadoras, porém admite que o tratamento de dados poderá ser efetivado sem o consentimento prévio, mas sim com o aviso posterior ao consumidor (art. $43, \S 2^{\circ}$ ). 
A doutrina pontua que "a legislação consumerista optou por conferir ao consumidor o direito de controlar as suas informações pessoais, seguindo o padrão regulatório acima referendado pelas FIPPs" (BIONI, 2018).

O presente artigo, entretanto, analisa a regra do CDC de forma mais crítica, pois se preocupa mais com a regulamentação dos Bancos de Dados do que com o consentimento prévio ao registro ou arquivamento dos mesmos, estando mais próxima das normas de primeira geração do que as de terceira. Ademais, a suposta autodeterminação informacional do consumidor resta ainda mais fragilizada a partir da Súmula no 404, do STJ, que adverte: "É dispensável o aviso de recebimento (AR) na carta de comunicação ao consumidor sobre a negativação de seu nome em bancos de dados e cadastros.”.

No mesmo viés do CDC, a Lei n. 9.507/97, que regulamenta o procedimento do Habeas Data, demonstra que o titular tem o direito de ter conhecimento das informações pessoais que constem em Bancos de Dados públicos (art. $7^{\circ}$ ), mas não deixa transparecer que é necessário o consentimento prévio do titular para o arquivamento de seus dados.

A Lei Complementar n. 105/2001, que trata do sigilo das operações de instituições financeiras, faz alusão ao consentimento do titular apenas para fins de revelação de “informações sigilosas" (art. $\left.1^{\circ}, \S 3^{\circ}, \mathrm{V}\right)$, mas admite uma série de situações em que os dados cadastrais dos clientes de bancos podem ser compartilhados entre as instituições, seja para fins de segurança ou verificação da prática de crimes, seja para fins exclusivamente econômicos (art. $1^{\circ}, \S 3^{\circ}$, I a IV). O pequeno prestígio do consentimento do titular, na legislação em comento, demonstra se tratar de lei de segunda geração.

No mesmo sentido, verifica-se o alto grau de risco à privacidade na regulamentação do Cadastro Único para Programas Sociais do Governo Federal - Decreto n. 6.135/07. A norma em questão, embora restrinja o uso dos dados cadastrais sigilosos das famílias às finalidades específicas admitidas no art. $8^{\circ}$, I e II (políticas públicas e realização de estudos e pesquisas), admite a "cessão" das bases de dados a outros órgãos públicos ( $\operatorname{art.} 8^{\circ}, \S 3^{\circ}$ ) e até mesmo a "terceiros" (art. $8^{\circ}, \S 4^{\circ}$ ). E, para tais transmissões de dados sigilosos, não há previsão da obrigatoriedade de consentimento prévio do titular.

Mais uma norma brasileira, portanto, que revela características da primeira geração de normas internacionais destinadas à proteção de dados privativos. A regulamentação do Cadastro Positivo (Lei $n^{\circ}$ 12.414/2011), ao revés, finalmente desponta para uma proteção 
mais efetiva e aproximada da quarta geração. Segundo o art. $4^{\circ}$, da norma supramencionada, “a abertura de cadastro requer autorização prévia do potencial cadastrado mediante consentimento informado por meio de assinatura em instrumento específico ou em cláusula apartada". Veja-se que a expressão "consentimento informado" demonstra a preocupação efetiva do legislador com a participação efetiva do titular dos dados processados.

Além da efetiva participação do cadastrado (exigência do consentimento expresso e informado), a lei cria órgãos responsáveis pela fiscalização da atividade e especifica os limites à utilização de dados, proibindo a anotação de informações "excessivas" ou "sensíveis" (art. $3^{\circ}, \S 3^{\circ}$ ), assim definidas pelo legislador: a) informações excessivas, assim consideradas aquelas que não estiverem vinculadas à análise de risco de crédito ao consumidor; e b) informações sensíveis, assim consideradas aquelas pertinentes à origem social e étnica, à saúde, à informação genética, à orientação sexual e às convicções políticas, religiosas e filosóficas.

A Lei do Cadastro Positivo, porém, é objeto de sensível reforma, através de projeto em trâmite final no Congresso Nacional (a última versão é o PLP n. 54/2019, aprovado no Senado Federal no último dia 13.03.2019³), que tem a finalidade de alterar o sistema de consentimento prévio para o "cadastro positivo".

O novo texto legal, que já passou pelas duas Casas Legislativas, agora segue para sanção presidencial, alterando substancialmente a versão original da Lei do Cadastro Positivo. O ponto central da alteração legislativa é justamente o consentimento do consumidor em relação ao uso de seus dados privativos. O projeto aprovado pelo Congresso Nacional, neste último mês de março de 2019, modifica, dentre outros dispositivos, justamente o art. $4^{\circ}$, para autorizar gestores das diversas instituições responsáveis por armazenamentos de dados a disponibilizar automaticamente tais informações para o cadastro positivo, independentemente de consentimento do consumidor cadastrado (sistema opt-out).

Assim, o cadastro positivo terá funcionamento próximo do que ocorre com o cadastro negativo. O consumidor será avisado que foi inscrito, mas o ato não depende de sua

\footnotetext{
${ }^{3}$ O PLP n. 54/2019 tem origem no PLS n. 212/2017, do próprio Senado Federal, que sofreu alterações na Câmara dos Deputados, quando passou a ter o número PLP n. 441/2017 e, finalmente, voltando ao Senado Federal, o projeto não sofreu mais alterações, e foi aprovado por 66 votos a 5 , na Sessão do último dia 13.03.2019. Disponível em https://www12.senado.leg.br/noticias/materias/2019/03/13/adesao-automatica-aocadastro-positivo-vai-a-sancao-presidencial . Acesso em: 19 mar. 2019.
} 
prévia autorização. A sistemática opt-out prevista no projeto que pretende alterar a Lei $\mathrm{n}^{\circ}$ 12.414/2011, se não for modificada por emendas e destaques de parlamentares antes da promulgação e sanção, impõe uma reanálise da compatibilidade da norma com os direitos da personalidade (especialmente o da privacidade - art. 21 , do CC), inclusive no que se refere à política de proteção ao consumidor.

Outra norma relevante para o estudo da proteção de dados privativos no Brasil é a Lei de Acesso à Informação (Lei n. 12.527/11), regulamentada pelo Decreto n. 7.724/12, que regulamenta o acesso do cidadão a informações no âmbito da Administração Pública Direta e Indireta, tratando a publicidade como preceito geral e do sigilo como exceção (art. $3^{\circ}, \mathrm{I}$ ).

Ao contrário do que se possa imaginar, a Lei de Acesso à Informação (LAI) não ofende o direito à privacidade de "informações pessoais", assim definidas como "aquela relacionada à pessoa natural identificada ou identificável” (art. 4\% IV). As chamadas “informações pessoais” recebem proteção especial quanto à segurança e inviolabilidade, nos termos do art. $6^{\circ}$, III.

Ademais, o art. 31, da LAI, assim como o art. 55, do Decreto n. 7.724/12, deixam claro que as informações pessoais, relativas inclusive à vida privada, só serão acessíveis com autorização expressa do titular.

Uma questão, porém, surgiu com o advento da LAI: é possível a divulgação, individualizada, da remuneração de servidores públicos? A questão foi dirimida pelo Supremo Tribunal Federal, em precedente com Relatoria do Ministro Carlos Ayres Britto, que, apreciando o pedido de Suspensão de Segurança AgR-SS n. 3902/DF, suspendeu liminar deferida em mandado de segurança impetrado pela Confederação dos Servidores Públicos do Brasil, a qual proibia a divulgação na internet dos rendimentos dos servidores federais dos Três Poderes.

Pela própria análise da Ementa do julgado, observa-se o posicionamento adotado pelo Pretório Excelso:

SUSPENSÃO DE SEGURANÇA. ACÓRDÃOS QUE IMPEDIAM A DIVULGAÇÃO, EM SÍTIO ELETRÔNICO OFICIAL, DE INFORMAÇÕES FUNCIONAIS DE SERVIDORES PÚBLICOS, INCLUSIVE A RESPECTIVA REMUNERAÇÃO. DEFERIMENTO DA MEDIDA DE SUSPENSÃO PELO PRESIDENTE DO STF. AGRAVO REGIMENTAL. CONFLITO APARENTE DE NORMAS CONSTITUCIONAIS. DIREITOÃ INFORMAÇÃO DE ATOS ESTATAIS, NELES EMBUTIDA A FOLHA DE PAGAMENTO DE ÓRGÃOS E 
ENTIDADES PÚBLICAS. PRINCÍPIO DA PUBLICIDADE ADMINISTRATIVA. NÃO RECONHECIMENTO DE VIOLAÇÃO À PRIVACIDADE, INTIMIDADE E SEGURANÇA DE SERVIDOR PÚBLICO. AGRAVOS DESPROVIDOS.

1. Caso em que a situação específica dos servidores públicos é regida pela $1^{\mathrm{a}}$ parte do inciso XXXIII do art. $5^{\circ}$ da Constituição. Sua remuneração bruta, cargos e funções por eles titularizados, órgãos de sua formal lotação, tudo é constitutivo de informação de interesse coletivo ou geral. Expondo-se, portanto, a divulgação oficial. Sem que a intimidade deles, vida privada e segurança pessoal e familiar se encaixem nas exceções de que trata a parte derradeira do mesmo dispositivo constitucional (inciso XXXIII do art. $5^{\circ}$ ), pois o fato é que não estão em jogo nem a segurança do Estado nem do conjunto da sociedade.

2. Não cabe, no caso, falar de intimidade ou de vida privada, pois os dados objeto da divulgação em causa dizem respeito a agentes públicos enquanto agentes públicos mesmos; ou, na linguagem da própria Constituição, agentes estatais agindo "nessa qualidade" ( $\$ 6^{\circ}$ do art. 37$)$. E quanto à segurança física ou corporal dos servidores, seja pessoal, seja familiarmente, claro que ela resultará um tanto ou quanto fragilizada com a divulgação nominalizada dos dados em debate, mas é um tipo de risco pessoal e familiar que se atenua com a proibição de se revelar o endereço residencial, o CPF e a CI de cada servidor. No mais, é o preço que se paga pela opção por uma carreira pública no seio de um Estado republicano.

3. A prevalência do princípio da publicidade administrativa outra coisa não é senão um dos mais altaneiros modos de concretizar a República enquanto forma de governo. Se, por um lado, há um necessário modo republicano de administrar o Estado brasileiro, de outra parte é a cidadania mesma que tem o direito de ver o seu Estado republicanamente administrado. O "como" se administra a coisa pública a preponderar sobre o "quem" administra - falaria Norberto Bobbio -, e o fato é que esse modo público de gerir a máquina estatal é elemento conceitual da nossa República. O olho e a pálpebra da nossa fisionomia constitucional republicana.

4. A negativa de prevalência do princípio da publicidade administrativa implicaria, no caso, inadmissível situação de grave lesão à ordem pública.

Veja-se que, no entendimento emanado pelo STF, que orienta a jurisprudência pátria desde o ano de 2011, não se considera ofensiva à privacidade do servidor público a divulgação de seus salários em sítios oficiais dos órgãos públicos aos quais estão vinculados.

Seguindo-se à análise das normas relacionadas à privacidade de informações pessoais, passa-se ao estudo do chamado Marco Civil da Internet (MCI - Lei n. 12.965/2014), regulamentado pelo Decreto n. 8.771/16. O Marco Civil da Internet é uma lei criada a partir dos estudos e diretrizes de responsabilidade do Comitê Gestor da Internet no Brasil, o CGi, fórum interministerial do Governo Federal constituído a partir do Decreto n. 4.829/2003.

Ao se promover uma interface comparativa entre a norma brasileira e a evolução do direito alienígena já apreciada no item anterior, observa-se que o MCI apresenta um alto grau de salvaguarda ao direito à privacidade, desde o estabelecimento dos seus Princípios norteadores (art. $3^{\circ}$, II e III). A inviolabilidade e o sigilo quanto aos dados pessoais, aos 
registros e fluxos das comunicações privadas pela internet é reiterado na sistematização dos direitos do usuário da rede, como se observada do art. $7^{\circ}$, I, II, III, VII, VIII e IX.

Especificamente em relação ao consentimento, o mencionado inciso IX destaca que fica assegurado ao consumidor de serviços de internet o direito ao "consentimento expresso sobre coleta, uso, armazenamento e tratamento de dados pessoais, que deverá ocorrer de forma destacada das demais cláusulas contratuais".

Além da consagração do sigilo de dados, e do protagonismo do titular quanto ao seu consentimento para tratamento de dados pessoais, a Lei n. 12.965/2014 se coaduna com a chamada $4^{a}$ fase das normas específicas sobre o tema, por conter outras garantias ao usuário, tais como: a) a nulidade de cláusulas contratuais que violem sua privacidade (art. $\left.8^{\circ}, \mathrm{I}\right)$; b) as sanções por eventuais descumprimentos da legislação (arts. 10 a 12, do MCI, além das regras previstas no Decreto n. 8.771/16); c) a responsabilização dos provedores de conexão e de aplicação (arts. 18 a 21); e d) a fixação de diretrizes para o Poder Público (arts. 24 a 28).

É preciso salientar, a partir da análise dos dispositivos legais previstos no MCI, que as diretivas apontadas ao Poder Público tentam estabelecer as competências das autoridades administrativas responsáveis pela fiscalização dos serviços de internet e eventuais sanções pelo descumprimento de normas.

Enfim, se um dado pessoal de um usuário receber tratamento na internet sem o seu consentimento prévio e expresso, qual seria a autoridade administrativa responsável pela apuração e eventual aplicação de sanções ao provedor ou banco de dados responsável?

No MCI, a resposta é genérica, pois os dispositivos legais tratam de "autoridade policial ou administrativa competente" (art. 12), mas remete para o Decreto n. 8.771/16 a regulamentação do procedimento de apuração de infrações (art. 11, $\S 4^{\circ}$ ). No referido Decreto, a fiscalização e a apuração de infrações são disciplinadas pelos artigos 17 a 21 .

A primeira autoridade indicada é a Agência Nacional de Telecomunicações, a ANATEL. Acontece que o próprio Decreto n. 8.771/16 deixa claro, no art. $5^{\circ}, \S 2^{\circ}$, que a agência "atuará na fiscalização e na apuração de infrações quanto aos requisitos técnicos elencados neste artigo, consideradas as diretrizes estabelecidas pelo Comitê Gestor da Internet - CGIbr.". Tais requisitos técnicos se referem à neutralidade da rede, e não à proteção de dados pessoais, como se vislumbra nos arts. $3^{\circ}$ a $9^{\circ}$ da norma regulamentadora. 
O segundo órgão público mencionado é a Secretaria Nacional do Consumidor (Senacon), que seria responsável pela fiscalização e apuração de infrações à Lei n. 8.078/90, o CDC. Acontece que a própria legislação consumerista é pouco aprofundada na proteção de dados pessoais, como já destacado no início do presente tópico. Por fim, o Sistema Brasileiro de Defesa da Concorrência não se refere à proteção de dados pessoais de usuários de internet, especificamente, e os arts. 20 e 21 trazem disposições genéricas.

Conclui-se, diante da análise acima, que o MCI, embora disponha expressamente sobre a necessidade do consentimento expresso para a coleta de dados pessoais dos usuários de internet (art. $7^{\circ}, \mathrm{IX}$ ), ainda assim é pouco consistente no que se refere à atuação do Poder Público quanto ao seu dever de fiscalização, apuração de infrações e sancionamento.

Por outro lado, a legislação esparsa e setorial só dificulta a tutela eficiente das pessoas que utilizam diariamente a rede mundial de computadores, fato que demonstrava a necessidade de uma norma direcionada especificamente à proteção de dados pessoais (RUARO, 2008, p. 60-61).

A expectativa por um marco regulatório da proteção de dados no Brasil tornou-se ainda mais premente com o surgimento do novo Regulamento Geral sobre a Proteção de Dados (RGPD ou GDPR, sigla em inglês) n. 2016/679, da União Europeia, datado de 2016 e em vigor desde o mês de maio de 2018.

Apenas para fins de exemplificação, o art. 45 do novo regulamento europeu dispõe que a transferência de dados pessoais para outro país da análise do nível de proteção constante na legislação do país destinatário.

Logo, a falta de uma regulamentação mais moderna e compatível no ordenamento jurídico brasileiro poderia dificultar as relações bilaterais entre o Brasil e os países europeus.

Neste cenário, finalmente, em 15 de agosto de 2018, foi publicada a Lei n. 13.709 (vigência após 18 meses - prevista para 16 de fevereiro de 2020, agora modificada para 24 meses, prevista para 16 de agosto de 2020, diante do advento da MP 869/2018), que dispõe sobre a proteção de dados pessoais.

A nova legislação traz um avanço significativo no âmbito da proteção da privacidade no espaço digital (PINHEIRO, 2018), cujo objeto se destaca no primeiro dispositivo legal da norma: esta lei dispõe sobre o tratamento de dados pessoais, inclusive nos meios digitais, por pessoa natural ou por pessoa jurídica de direito público ou privado, com o objetivo de 
proteger os direitos fundamentais de liberdade e de privacidade e o livre desenvolvimento da personalidade da pessoa natural $\left(\operatorname{art} .1^{\circ}\right)$. Os dois primeiros "fundamentos" da norma são, justamente, o respeito à privacidade (art. $\left.2^{\circ}, \mathrm{I}\right)$ e a autodeterminação informativa (art. $\left.2^{\circ}, \mathrm{II}\right)$.

Em complemento, avultam na LGPD os princípios estabelecidos no art. $6^{\circ}$, referentes aos procedimentos éticos e responsáveis que se esperam daqueles que manuseiam dados pessoais no espaço digital: finalidade, adequação, necessidade, livre acesso, qualidade dos dados, transparência, segurança, prevenção, não discriminação, responsabilização e prestação de contas.

Consoante já reiterado nos parágrafos anteriores, o Autor pretende analisar o papel do consentimento no arcabouço legal agora complementado pela LGPD.

A premissa estabelecida no novel estatuto segue a tendência de exigir o consentimento livre, informado e inequívoco do titular para o tratamento de seus dados pessoais, como já se vislumbrou no art. $2^{\circ}$, II e no art. $5^{\circ}$, XII.

Em complemento, o art. $8^{\circ}$ estabelece que "o consentimento previsto no inciso I do art. $7^{\circ}$ desta Lei deverá ser fornecido por escrito ou por outro meio que demonstre a manifestação de vontade do titular". Neste sentido, a Lei Geral de Proteção de Dados lista o consentimento do titular como um dos requisitos essenciais para o tratamento de informações pessoais (art. $7^{\circ}, \mathrm{I}$ ), salvo nos casos em que a própria LGPD é inaplicável (art. $4^{\circ}$ ). Não é, porém, a única exigência para o tratamento de um dado pessoal, pois o consentimento prévio faz parte de uma lista de dez parâmetros previstos no art. $7^{\circ}$, I a X, da LGPD.

Por outro lado, é admitida excepcionalmente a utilização de dados sem a prévia anuência do titular, desde que este seja avisado posteriormente de forma clara e precisa, nas hipóteses constantes no próprio dispositivo (art. $7^{\circ}, \S \S 1^{\circ}$ a $6^{\circ}$ ).

O certo é que o consentimento prévio, ainda que numa disciplina menos rígida que o GPDR (que exige o exige de forma "expressa" e "específica") segue como um dos requisitos determinantes para o tratamento de dados pessoais por qualquer pessoa física ou jurídica que atue como controlador ou operador de informações na rede ou banco de dados. A aproximação com o marco regulatório europeu e a própria carga principiológica da LGPD, além da preocupação com a privacidade do indivíduo, demonstram o enquadramento da norma quarta geração de leis protetivas de dados pessoais (BIONI, 2018). 
É preciso, porém, analisar essa suposta supremacia do titular, através do fundamento legal da "autodeterminação informativa", em um viés mais crítico e aprofundado.

Ora, o direito à autodeterminação informativa não é suficiente para evitar o fornecimento compulsório de dados para a prática dos atos mais corriqueiros de qualquer pessoa física: adquirir um telefone móvel, contratar serviços públicos essenciais, extrair documentos em órgãos públicos, prestar concursos, possuir conta bancária, etc.

Logo, a "fé" no consentimento prévio como redoma protetora da privacidade do titular é puramente teórica, e baseada na extrema confiança de que os controladores e operadores de dados irão respeitar todos os ditames da LGPD. Esse ceticismo quanto à proteção do titular pelo simples fato do tratamento de dados depender de seu consentimento pode ser verificado tanto na doutrina pátria quanto na alienígena, que reconhecem a vulnerabilidade do titular e a fragilidade da proteção legal.

Em obra recente, Bruno Ricado Bioni (2018, p. 165-167) analisou os resultados de pesquisas realizadas pelas Universidades de Stanford e Carnegie Mellon, Berkeley e Pensilvânia, chegando à conclusão de que:

\begin{abstract}
Por isso, aponta-se que o consumidor é (hiper)vulnerável em meio a esse mercado informacional. (...) A sobreposição de vulnerabilidades tem reclamado a sobreposição de regimes legais. (...) É curioso notar, no entanto, que a estratégia regulatória dessa explosão normativa de proteção de dados pessoais segue uma lógica contrária à constatação da (hiper)vulnerabilidade do titular dos dados pessoais. Muito embora se dedique um diploma próprio para tratar dessa situação específica de vulnerabilidade, apostam-se todas as fichas normativas como se a parte mais fraca desse arranjo regulatório fosse um sujeito racional, livre e capaz de fazer valer a proteção de seus dados pessoais. O protagonismo do consentimento encerra, portanto, uma contradição (intrínseca) desse ambiente ou estratégia regulatória.
\end{abstract}

No mesmo sentido, compreendendo a complexidade da proteção do indivíduo que se expõe a consentir ou não com a utilização de um dado pessoal no mercado da informação, pontua SOLOVE D. J. (2012) as pessoas não leem as políticas de privacidade e, se as leem, não as compreendem. Também observa que mesmo compreendendo as políticas de privacidade, elas não têm conhecimento suficiente para fazer uma escolha informada, ou mesmo essa escolha pode ser distorcida diante das dificuldades da tomada de decisão.

Além da dificuldade para que o consumidor ou usuário da rede tenha condições efetivas para decidir, nunca é demais lembrar que o próprio legislador estabelece que o 
consentimento expresso poderá ser proferido em cláusula contratual (art. $8^{\circ}, \S 1^{\circ}$ ). Nas relações de massa típicas da sociedade da informação, trais contratos são essencialmente "de adesão", na maioria dos casos virtuais, cabendo ao titular dos dados apenas decidir se “concorda" ou não, "clicando" na opção "li e aceito". Como aponta RODOTÀ (2008), é raro o cidadão ser capaz de perceber os riscos que corre ao fornecer seus dados, muito menos o potencial de tais informações pessoais para as organizações coletoras, diante da complexidade dos sistemas sofisticados de tratamento.

Enfim, o protagonismo do cidadão, que decide se fornece ou não seus dados, é claramente questionável, na prática, invocando-se uma verdadeira "crise do consentimento" (SCHERMER.; CUSTERS; e HOF. S., 2014).

Reconhecer essa complexidade é essencial para: a) primeiro, reconhecer que o consentimento prévio, expresso e informado é um avanço, mas não garante proteção ao titular de dados privativos no mercado informacional; e b) é preciso fortalecer as autoridades fiscalizatórias e punitivas, responsabilizadas pelo cumprimento das normas previstas nos estatutos de proteção de dados pessoais.

\section{A CRIAÇÃo da AUTORIDAde NACIONAL DE PROTEÇÃo DE DAdos. ANÁLISE PRELIMINAR DA MEDIDA PROVISÓRIA N. 869/2018:}

Se a exigência de consentimento prévio é uma razoável garantia de proteção ao titular de dados privativos na rede, restou destacada no item anterior existem exceções previstas na própria legislação, e, mais importante, vislumbra-se uma flagrante dificuldade para o consumidor médio sentir-se seguro para decidir se aceita ou não o tratamento de seus dados pessoais, bem como se esse indivíduo compreende as consequência do permissivo.

Seguindo a linha mais atual da tutela da privacidade na rede mundial de computadores, a LGPD determinou a criação, no Capítulo IX, da Autoridade Nacional de Proteção de Dados (ANPD) e do Conselho Nacional de Proteção de Dados Pessoais e da Privacidade, observando-se que a ANPD que seria uma Pessoa Jurídica de Direito Público (art. 41, do CC), com Personalidade Jurídica própria, integrante da Administração Pública Federal Indireta, submetida a regime autárquico especial e vinculada ao Ministério da Justiça. 
A natureza jurídica ANPD lhe garantiria independência financeira e administrativa, salutar para o desempenho das funções que lhe seriam outorgadas.

Dentre suas várias atribuições, destacava-se a responsabilidade por "fiscalizar e aplicar sanções em caso de tratamento de dados realizado em descumprimento à legislação, mediante processo administrativo que assegure o contraditório, a ampla defesa e o direito de recurso" (art. 56, IV). Acontece que os dispositivos (arts. 55 a 59) foram vetados, porque "incorrem em inconstitucionalidade do processo legislativo, por afronta ao artigo 61, § $1^{\circ}$, II, 'e', cumulado com o artigo 37, XIX da Constituição". ${ }^{4}$

$\mathrm{O}$ veto, portanto, consubstanciou-se na norma constitucional que consagra a iniciativa privativa do Presidente da República para leis que disponham sobre a criação de órgãos da administração pública (art. 61, $\S 1^{\circ}$, II, 'e', da CF), estendendo a interpretação do dispositivo à criação de autarquias, nos termos do art. 37, XIX, da mesma Carta Magna (vício de inconstitucionalidade formal).

Sem adentrar nas razões jurídicas do veto, é de ver-se que a não criação da Autoridade Nacional de Proteção de Dados tornaria inócua a atividade fiscalizatória da administração pública, como dispunha o Marco Civil da Internet e também prevê a própria LGPD, como já vem pontuando a doutrina (COTS e OLIVEIRA, 2018).

Pouco mais de quatro meses depois da publicação da LGPD, porém, foi publicada, no D.O.U. de 28.12.2018, a Medida Provisória n. 869/2018, que criou a Autoridade Nacional de Proteção de Dados e o Conselho Nacional de Proteção de Dados Pessoais e da Privacidade, alterando alguns dispositivos da LGDP e acrescentando os arts. 55-A a 55-K, bem como os arts. 58-A e 58-B. Até o fechamento desse artigo, o Congresso Nacional ainda não havia convertido a Medida Provisória n. 869/2018 em lei.

A Autoridade Nacional de Proteção de Dados (ANPD) criada pela Medida Provisória n. 869/2018, entretanto, contém distinções relevantes, se comparada à versão original prevista no Projeto de Lei do Senado n. 53/2018, senão vejamos:

\begin{tabular}{|l|l|}
\hline \multicolumn{1}{|c|}{ ANPD no PL n. 53/2018 (vetado) } & \multicolumn{3}{|c|}{ ANPD na MP 869/2018 (vigente) } \\
\hline $\begin{array}{l}1-\text { Autarquia Especial vinculada ao Ministério da } \\
\text { Justiça; }\end{array}$ & $\begin{array}{l}1 \text { Órgão público federal, integrante da } \\
\text { Presidência da República; }\end{array}$ \\
\hline
\end{tabular}

\footnotetext{
${ }^{4}$ Mensagem de veto à Lei n. 13.709/2018. Disponível em http://www.planalto.gov.br/ccivil_03/_Ato20152018/2018/Msg/VEP/VEP-451.htm. Acesso em: 12 dez. 2018.
} 


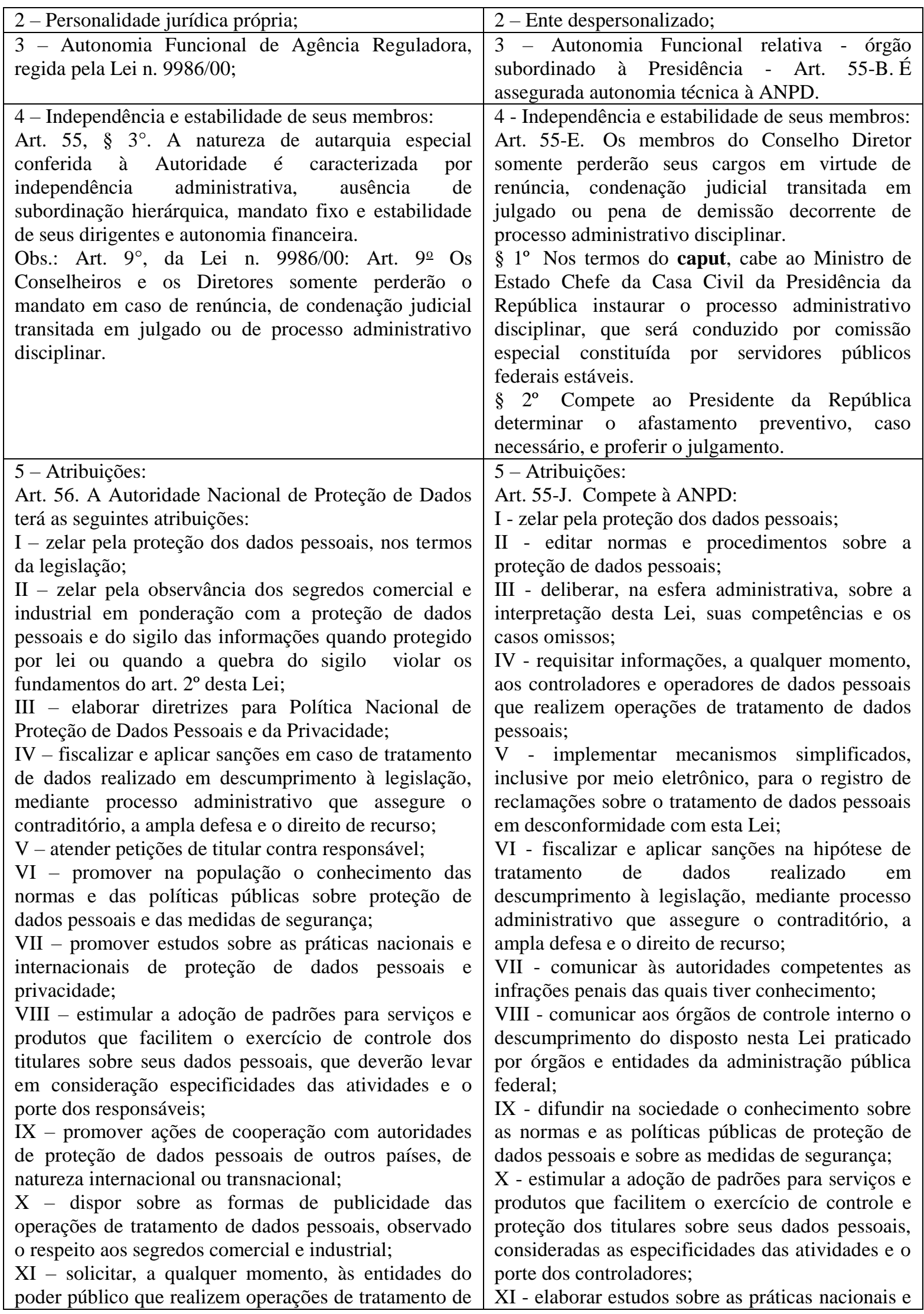


dados pessoais, informe específico sobre o âmbito, a natureza dos dados e

os demais detalhes do tratamento realizado, podendo emitir parecer técnico complementar para garantir o cumprimento desta Lei;

XII - elaborar relatórios de gestão anuais acerca de suas atividades;

XIII - editar regulamentos e procedimentos sobre proteção de dados pessoais e privacidade, assim como sobre relatórios de impacto à proteção de dados pessoais para os casos em que o tratamento representar alto risco para a garantia dos princípios gerais de proteção de dados pessoais previstos nesta Lei;

XIV - ouvir os agentes de tratamento e a sociedade em matérias de interesse relevante, assim como prestar contas sobre suas atividades e planejamento;

$\mathrm{XV}$ - arrecadar e aplicar suas receitas e publicar no relatório de gestão a que se refere o inciso XII do caput deste artigo o detalhamento de suas receitas e despesas; e

XVI - realizar ou determinar a realização de auditorias, no âmbito da atividade de fiscalização, sobre o tratamento de dados pessoais efetuado pelos agentes de tratamento, incluindo o poder público.

6 - Recursos para o funcionamento da Autarquia Especial:

Art. 57. Constituem receitas da Autoridade Nacional de Proteção de Dados:

I - o produto da execução da sua dívida ativa;

II - as dotações consignadas no orçamento geral da União, os créditos especiais, os créditos adicionais, as transferências e os repasses que lhe forem conferidos; III - as doações, legados, subvenções e outros recursos que lhe forem destinados;

IV - os valores apurados na venda ou aluguel de bens móveis e imóveis de sua propriedade;

$\mathrm{V}$ - os valores apurados em aplicações no mercado financeiro das receitas previstas neste artigo;

VI - o produto da cobrança de emolumentos por serviços prestados;

VII - os recursos provenientes de acordos, convênios ou contratos celebrados com entidades, organismos ou empresas, públicos ou privados, nacionais e internacionais;

VIII - o produto da venda de publicações, material técnico, dados e informações, inclusive para fins de licitação pública. internacionais de proteção de dados pessoais e privacidade;

XII - promover ações de cooperação com autoridades de proteção de dados pessoais de outros países, de natureza internacional ou transnacional;

XIII - realizar consultas públicas para colher sugestões sobre temas de relevante interesse público na área de atuação da ANPD;

XIV - realizar, previamente à edição de resoluções, a oitiva de entidades ou órgãos da administração pública que sejam responsáveis pela regulação de setores específicos da atividade econômica;

$\mathrm{XV}$ - articular-se com as autoridades reguladoras públicas para exercer suas competências em setores específicos de atividades econômicas e governamentais sujeitas à regulação; e

XVI - elaborar relatórios de gestão anuais acerca de suas atividades.

6 - Recursos para o funcionamento da Órgão Público:

Não há previsão sequer de aumento de despesa para a criação da ANPD, órgão vinculado à Presidência, nos termos do art. 55-A, da LGPD, com a redação da MP n. 869/2018.

A análise da tabela acima demonstra que, embora tenham atribuições similares, a ANPD originária do Projeto de Lei do Senado n. 53/2018 era uma Autarquia Especial regida subsidiariamente pela Lei das Agências Reguladoras, com maior independência funcional e 
estrutural, até mesmo porque contava com receitas orçamentárias preestabelecidas, como se vislumbra do art. 57, transcrito na última linha do quadro supra delineado.

Enfim, uma autarquia especial com personalidade jurídica própria e estrutura funcional mais robusta e independente gozaria de uma menor pressão política que a de um órgão público vinculado diretamente à Presidência da República, ainda que garantida, na lei, a autonomia técnica.

Numa análise de direito comparado, o Projeto de Lei do Senado n. 53/2018 possuía, no Capítulo IX que infelizmente fora vetado, uma normatização que estaria muito próxima da regulamentação das Autoridades de Controle previstas na GDPR (General Data Protection Regulation) n. 2016/679, em seu Capítulo VI, arts. 51 a 59, órgãos independentes (inclusive em termos orçamentários) com poderes investigativos, fiscalizatórios e sancionadores.

Recente artigo publicado na revista eletrônica Jota (LEMOS, Ronaldo et al, 2018), uma dia após a publicação da indigitada MP, já prenunciava as preocupações da doutrina especializada sobre a nova ANPD, senão vejamos:

\begin{abstract}
Ressaltamos, todavia, que entre as principais razões para a necessidade de criação da própria Autoridade está justamente sua atuação como instância regulatória capaz de apresentar opiniões técnicas específicas à proteção da privacidade nos diferentes segmentos de mercado, e de realizar controle unificado e homogêneo do cumprimento das disposições da LGPD, independentemente de quaisquer vinculações políticas ou ideológicas ou pressões de setores específicos. [...] Nesse sentido, assim como no texto original da LGPD, a MP prevê que a Autoridade contará com Conselho Diretor, Conselho Nacional de Proteção de Dados e da Privacidade e com Unidades especializadas à aplicação da Lei. Todavia, por compor a administração direta e também porque o texto da MP expressamente restringe a possibilidade de sua criação resultar em aumento de despesas (art. 55-A), a Autoridade não contará com autonomia financeira, resultando na restrição de sua capacidade em empreender medidas destinadas à consecução de seus objetivos institucionais. [...] Diante disso, consideramos que o desenho institucional previsto na MP para a Autoridade pode prejudicar atividades envolvendo também a transferência internacional de dados.
\end{abstract}

Como ponto positivo da MP, preciso destacar que, se, de um lado elasteceu o prazo de vacatio legis da LGDP, de 18 meses para 24 meses, de outro viés entendeu por bem conceder vigência imediata aos dispositivos legais que criaram a ANPD e o Conselho Nacional de Proteção de Dados Pessoais e da Privacidade, conforme art. 65, da LGPD, na redação constante a partir de 28.12.2018. 
Nunca é demais lembrar, porém, que a MP n. 869/2018 será apreciada pelo Poder Legislativo antes de ser convertida, ou não, em lei, havendo, por conseguinte, espaço para a promoção de mudanças em seu texto, se mais ou menos alinhadas ao texto original vetado.

Até o fechamento do presente artigo, a Medida Provisória ainda estava em pleno vigor, pendente de apreciação legislativa competente.

Esse é o quadro atual do microssistema legislativo de proteção de dados pessoais, lastreado em uma proteção teórica e principiológica, porém com pouca efetividade, seja pelas restrições que os consumidores enfrentam para exercer um consentimento prévio efetivamente consciente, eficaz e informado, seja pela quantidade de exceções à regra do consentimento prévio, seja pela aparente fragilidade da nova Autoridade Nacional de Proteção de Dados, a ANPD, criada pela MP n. 869/2018, examinada especificamente neste último capítulo.

\section{CONSIDERAÇÕES FINAIS}

O texto ora apresentado tem como base o estudo do direito à privacidade, direito humano, fundamental e da personalidade de qualquer cidadão, como um dos paradigmas para uma vida digna. Dentre os diversos aspectos do direito à vida privada, o trabalho analisou a proteção dos dados pessoais na rede mundial de computadores, a partir da legislação recentemente produzida no Brasil e em outros países, especialmente no bloco europeu, cuja recente regulamentação (2016) influenciou sobremaneira a nova Lei Geral de Proteção de Dados do país (2018, com vigência a partir de 2020, depois de 24 meses da publicação, se for mantida a nova disciplina da MP n. 869/2018, datada de 28.12.2018).

O avanço da positivação do tema é considerável, e vem sendo desenvolvido há alguns anos, consoante conjunto normativo que foi estudado no item anterior. As considerações sobre esse microssistema legislativo de proteção de dados pessoais seria sobremaneira ampla, mas o presente artigo delimitou suas reflexões sobre o papel do consentimento do titular de tais informações personalíssimas, como exigência legal para o tratamento de tais dados pelos operadores e controladores da rede mundial de computadores, sejam eles pessoas físicas ou jurídicas, de caráter público ou privado.

Se a exigência de consentimento expresso, prévio e informado, como consta na legislação mais recente, é um fator positivo para a tutela da privacidade dos indivíduos, por 
outro lado, como destacado no último subtítulo (2.3), revela-se, isoladamente, pouco eficiente para uma real proteção dos dados pessoais do usuário.

Vislumbra-se, também, seja na legislação vigente, seja nas normas vindouras, especialmente quanto às alterações previstas para a Lei de Cadastro Positivo, aprovadas recentemente no Senado Federal e prontas para a sanção presidencial, que será aberto mais um flanco para o sistema opt-out, que prescinde da prévia anuência do consumidor para sua inclusão nos bancos de dados positivos, medida defendida como relevante no aspecto econômico das relações creditícias.

Compreende-se, nesta dicção, que é necessário o reforço na fiscalização por meio da Administração Pública integrada, em face da atividade de tratamento de dados, à luz dos objetivos, fundamentos e princípios da LGPD e demais marcos regulatórios do mercado informacional. Neste particular, foi especialmente decepcionante o veto presidencial ao Capítulo IX, da Lei n. 13.709/18, justamente o que previa a criação de autarquia especial para o exercício da fiscalização e controle do cumprimento da norma geral protetiva dos dados privativos.

Para compensar o veto que foi publicado juntamente com a LGPD, em agosto de 2018, foi editada a MP n. 869/2018, que finalmente criou a Autoridade Nacional de Proteção de Dados (ANPD), porém com distinções em relação à redação original, aparente fragilizando, em estrutura e independência, o novo órgão federal constante nos acrescidos arts. 55-A a 55-K, da LGDP.

Se a MP for convertida em lei, tanto a ANPD quanto o Conselho Nacional de Proteção de Dados Pessoais e da Privacidade (arts. 58-a e 58-B) passam a vigorar imediatamente, enquanto o restante da LGDP teve sua vacatio legis alterada de 18 meses para 24 meses. Logo, será possível avaliar a efetividade de tais Órgãos Federais antes mesmo da entrada em vigor da própria LGDP.

Enfim, vislumbra-se, por todo o exposto, que o consentimento prévio do titular para o tratamento de seus dados é uma proteção deveras relativa e limitada, e a fiscalização estatal esboça, até o momento, uma eficiência pouco promissora, que só será possível confirmar com o decurso do tempo.

Conclui-se, portanto, pelo reconhecimento da importância da norma geral de proteção dos dados pessoais dos indivíduos em meio à sociedade digital, sem, contudo, deixar 
de demonstrar as falhas normativas e limitações do sistema, até mesmo diante da complexidade da tarefa de regulamentar e controlar o imenso e disperso fluxo de informações no mundo hodierno.

\section{REFERÊNCIAS}

ANDRADE, Diogo de Calasans Melo. As redes sociais: o direito à privacidade versus a liberdade: uma análise histórico-jurídica desses princípios e a supremacia da constituição. Conpedi Salvador, 2018.

ANDRADE, Diogo de Calasans Melo. Direito ao esquecimento como direito da personalidade versus liberdade de expressão como direito à informação, Revista Interfaces Direito, 2016.

ANDRIGH, Fátima Nancy. A responsabilidade civil dos provedores de pesquisa via internet. Rev. TST, Brasília, vol. 78, no 3, jul/set 2012, p, 64-75.

BARBOSA, Denis Borges. Direito da Inovação. 2. ed. Rio de Janeiro: Lumen Juris, 2011.

BECK, Ulrich. Sociedade do Risco: rumo a uma outra modernidade. São Paulo: Editora 34, 2010.

Bessa, Leonardo Roscoe. Cadastro Positivo: Comentários à lei 12,414, de 09 de junho de 2011. São Paulo: Editora Revista dos Tribunais, 2011.

BLUM, Renato Opice; MALDONADO, Viviane Nóbrega. Comentários ao GDPR Regulamento Geral de Proteção de Dados da União Europeia. São Paulo: Editora Revista dos Tribunais, 2018.

BRASIL. Artigo 21. Código Civil. Promulgado em 10 de janeiro de 2002. Disponível em: < http://www.planalto.gov.br/ccivil_03/Leis/L8078.htm> Acesso em: 02 ago. 2018.

BRASIL. Artigos 43 e 44. Código de Defesa do Consumidor. Promulgado em 11 de setembro de 1990. Disponível em: < http://www.planalto.gov.br/ccivil_03/Leis/L8078.htm> Acesso em: 02 ago. 2018.

BRASIL. Artigo 5 $5^{\circ}$ Constituição Federal de 1988. Promulgada em 5 de outubro de 1998. Disponível em: http://www.planalto.gov.br/ccivil_03/constituicao/constituicaocompilado.htm . Acesso em: 02 ago. 2018.

BRASIL. Lei n. 9.507/97. Promulgada em 12 de novembro de 1997. Disponível em: http://www.planalto.gov.br/ccivil_03/LEIS/L9507.htm. Acesso em: 02 ago. 2018. 
BRASIL. Lei Complementar n. 105/2001. Promulgada em 10 de janeiro de 2001. Disponível em: http://www.planalto.gov.br/ccivil_03/leis/lcp/Lcp105.htm.Acesso em: 02 ago. 2018.

BRASIL. Lei n. 12.414. Promulgada em 09 de junho de 2011. Disponível em: http://www.planalto.gov.br/ccivil_03/_Ato2011-2014/2011/Lei/L12414.htm. Acesso em: 02 ago. 2018.

BRASIL. Lei n. 12.527/11. Promulgada em 18 de novembro de 2011. Disponível em: http://www.planalto.gov.br/ccivil_03/_ato2011-2014/2011/lei/112527.htm. Acesso em: 02 ago. 2018.

BRASIL. Decreto n. 7.724/12. Promulgado em 16 de maio de 2012. Disponível em: http://www.planalto.gov.br/ccivil_03/_ato2011-2014/2012/Decreto/D7724.htm. Acesso em: 02 ago. 2018.

BRASIL. Lei n. 12.965. Promulgada em 23 de abril de 2014. Disponível em: http://www.planalto.gov.br/ccivil_03/_Ato2011-2014/2014/Lei/L12965.htm. Acesso em: 02 ago. 2018.

BRASIL. Lei n. 13.709/18. Promulgada em 14 de agosto de 2018. Disponível em: http://www.planalto.gov.br/ccivil_03/_Ato2015-2018/2018/Lei/L13709.htm. Acesso em: 19 mar. 2019.

BRASIL. Supremo Tribunal Federal. SS 3902 AgR-segundo, Relator(a): Min. AYRES BRITTO, Tribunal Pleno, julgado em 09/06/2011, DJe-189 DIVULG 30-09-2011 PUBLIC 03-10-2011 EMENT VOL-02599-01 PP-00055 RTJ VOL-00220-01 PP-00149.

CASTELLS, Manuel. A Sociedade em Rede. Trad. Roneide Venâncio Majer. São Paulo: Paz e Terra, 2006.

CASTELLS, Manuel. A Galáxia Internet: reflexões sobre internet, negócios e sociedade. Tradução: Rita Espanha. Editora: Fundação Calouste, Lisboa, 2004.

CAVAlCANTI, N. P.; SANTOS, L. M. da S. B. A Lei Geral de Proteção de Dados do Brasil na era do Big Data. In: FERNANDES, Ricardo Vieira de Carvalho; CARVALHO, Angelo Gamba Prata de (Coord.). Tecnologia jurídica \& direito digital: II Congresso Internacional de Direito, Governo e Tecnologia - 2018. Belo Horizonte: Fórum, 2018, p. 351365 .

COTS, Márcio; OLIVEIRA, Ricardo. Lei Geral de Proteção de Dados Comentada. São Paulo: Editora Revista dos Tribunais, 2018.

DONEDA, Danilo. A proteção dos dados pessoais como um direito fundamental. Espaço jurídico, Joaçaba, v. 12, n. 2, p. 91-108, jul./dez. 2011. Disponível em: http://editora.unoesc.edu.br/index.php/espacojuridico/article/view/1315. Acesso em: 20.nov.2018. 
FARIAS, Cristiano Chaves de; Netto, Felipe Braga; e ROSENVALD, Nelson. Manual de Direito Civil. v. único. 2. ed. Salvador: JusPodivm, 2018;

FRANÇA, Rubens Limongi. Direitos da personalidade: coordenadas fundamentais. Revista do Advogado, n. 38, p. 45-59, dez. 1992.

FRAZÃO, Ana. Nova LGPD: balanço preliminar da MP 869/2018. Jota, 06/02/2019. Disponível em: https://www.jota.info/opiniao-e-analise/colunas/constituicao-empresa-emercado/nova-lgpd-balanco-preliminar-da-mp-869-2018-06022019. Acesso em: 20 mar. 2019.

GOMES, Orlando. Direitos da personalidade. Revista de Informação Legislativa, Brasília, v. 3, n. 11, p. 39-48, set. 1966.

LEMOS, Ronaldo. Marco Civil da Internet: jurisprudência comentada, Responsabilidade civil dos provedores da internet. São Paulo: RT, 2017.

LEMOS, Ronaldo; DOUEK, Daniel; ADAMI, Mateus Piva; LANGENEGGER, Natalia; FRANCO, Sônia Lima. A criação da Autoridade Nacional de Proteção de Dados pela MP $\mathbf{n}^{\mathbf{0}}$ 869/2018. Jota, 29/12/2018. Disponível em < https://www.jota.info/opiniao-eanalise/artigos/a-criacao-da-autoridade-nacional-de-protecao-de-dados-pela-mp-no-869-2018$29122018>$. Acesso em 20.03.2019.

LEONARDI, Marcel. Responsabilidade civil dos provedores de serviços de Internet, São Paulo: Juarez, 2005.

LÉVY, Pierre. As tecnologias da inteligência: o futuro do pensamento na era da informática, 15..reimpr. Rio de Janeiro: Ed. 34, 2008.

MENDES, Laura Schertel. Privacidade, proteção de dados e defesa do consumidor: linhas gerais de um novo direito fundamental. São Paulo: Saraiva, 2014.

MURILLO DE LA CUEVA, P. L. Derechos fundamentales y avances tecnológicos: Los riesgos del progreso. Boletín Mexicano de Derecho Comparado, no. 109, p. 72-110, 2004.

NASCIMENTO, Valéria Ribas do. Direitos fundamentais da personalidade na era da sociedade da informação. RIL Brasília a. 54 n. 213 jan./mar. 2017 p. 265-288.

OLIVEIRA, Carlos Eduardo Elias de. Aspectos principais da lei $\mathbf{n}^{\mathbf{0}}$ 12.965, de 2014, o marco civil da internet: subsídios à comunidade jurídica. Textos para Discussão 148 Abril/2014, Senado Federal, p. 5-25.

PINHEIRO, Patrícia Peck. Proteção de Dados Pessoais: comentários à lei n. 13.709/2018 (LGPD). São Paulo: Saraiva, 2018. 
RODOTÀ, Stefano. A vida na sociedade da vigilância - a privacidade hoje. Organização, seleção e apresentação de Maria Celina Bodin de Moraes. Tradução: Danilo Doneda e Luciana Cabral Doneda - Rio de Janeiro: Renovar, 2008.

RUARO, Regina Linden. O direito à proteção de dados pessoais e a privacidade. Revista da Faculdade de Direito - UFPR, Curitiba, n.47, p.29-64, 2008.

SCHEREIBER, Anderson. Direitos da Personalidade. Rio de Janeiro: Atlas, 2014.

SCHERMER, B. W.; CUSTERS, Bart; HOF. S, van der. The Crisis of Consent: How Stronger Legal Protection May Lead to Weaker Consent in Data Protection (February 25, 2014). Ethics and Information Technology. DOI: 10.1007/s10676-014-9343-8, Disponível em: < https://papers.ssrn.com/sol3/Data_Integrity_Notice.cfm?abid=2412418 > Acesso em: 20.nov.2018..

SOLOVE, Daniel J. Introduction: Privacy self-management and the consent dilemma. Harv. L. Rev., v. 126, p. 1880, 2012.

SZANIAWSKI, Elimar. Direitos da Personalidade e sua tutela. São Paulo: Revista dos Tribunais, 2005.

WARREN, Samuel D.; BRANDEIS, Louis D. The right to privacy. Harvard Law Review. n. 5, p. 123-220, dez. 1890 . 